\title{
ESTUDOS
}

\section{Comunicação e arte, ou a arte da comunicação, em John Dewey*}

Marcus Vinicius da Cunha

Palavras-chave: comunicação e ensino; arte e educação; teorias do conhecimento; retórica. * Trabalho decorrente de pesqui-
sas subsidiadas pelo Conselho
Nacional de Desenvolvimento
Científico e Tecnológico
(CNPq).

\section{Resumo}

Busca contribuir para elucidar as idéias de John Dewey contidas na formulação que vincula educação, comunicação e arte. Além disso, como aporte metodológico, procura mostrar que todo texto deve ser abordado em suas estratégias discursivas, como um conjunto articulado para afirmar determinados conceitos. O ponto de partida é a relevância atribuída à comunicação no processo educativo, conforme estabelecido por Dewey em Democracia e Educação. A análise desse livro e de outras obras do autor possibilita elucidar os conceitos de ciência e arte, bem como o método de ensino proposto por Dewey. A título de conclusão, sugere-se que a continuidade da investigação deva abordar os conceitos deweyanos em seus possíveis vínculos com a filosofia grega.

\section{Introdução}

O objetivo imediato deste trabalho é contribuir para elucidar as concepções de John Dewey contidas na formulação que vincula educação, comunicação e arte. Além disso, sob a inspiração de Perelman e OlbrechtsTyteca (2002), pretende-se mostrar que um texto deve ser analisado por meio dos recursos discursivos que emprega para capturar o leitor na teia dos conceitos que busca afirmar. No presente estudo, elege-se como centro de análise a relevância atribuída à comunicação no processo educativo, conforme explicitado por Dewey no livro Democracia e Educação, de 1916, uma de suas obras fundamentais. Esse procedimento permite adentrar nas significações do próprio texto e visualizar os fios que levam a outros escritos do autor, com destaque para Philosophy of Education, de 1946, coletânea de artigos publicados entre 1935 e meados da década de 1940, representativa da última fase de sua produção intelectual. O tema comunicação conduz às noções de ciência e arte, entre outras, bem como à elucidação do método de ensino sugerido por Dewey. Por essa via chega-se, por fim, não a uma conclusão propriamente dita, mas a indicações para futuras pesquisas: sugere-se que o esforço para deslindar a teia conceitual deweyana deva ter continuidade no estudo de seus possíveis vínculos com a filosofia grega, particularmente no âmbito da sistematização elaborada por Aristóteles.

\section{Comunicação, socialização e educação}

No primeiro capítulo da edição brasileira de Democracia e Educação (Dewey, 1959a, p. 4), lê-se: "A sociedade não só continua a existir pela transmissão, pela comunicação, como também se pode perfeitamente dizer que ela é transmissão e é comunicação". No original, em língua inglesa, a frase é "Society not only continues to exist by 
transmission, by communication, but it may fairly be said to exist in transmission, in communication" (Dewey, 1997, p. 4). ${ }^{1}$ Como se pode notar, a versão dos tradutores Godofredo Rangel e Anísio Teixeira para "to exist in transmission, in communication" não corresponde literalmente às palavras do autor, mas busca expressar a idéia de que a comunicação não garante tão-somente a continuidade da sociedade, mas a sua própria existência como tal. ${ }^{2}$ A sociedade torna-se o que é por intermédio da comunicação.

Mesmo sem enunciar que sociedade é comunicação, o intuito de Dewey é estabelecer um vínculo estreito entre os dois termos, de tal modo que se torne possível visualizar a identificação de um com outro - e esta deve ter sido a intenção dos tradutores. Para Dewey, uma sociedade se faz como tal quando integra seus pretensos membros, transformando-os em seres pertencentes a um dado agrupamento. E isto se faz, fundamentalmente, por meio da comunicação, processo que comporta não só linguagem falada e escrita, mas todo um conjunto de sinais que expressam valores e conhecimentos e cumprem a função de tornar a experiência um patrimônio comum, partilhado e desfrutado por todos. "Há mais do que um nexo verbal entre os termos comum, comunidade e comunicação", diz o autor, pois para haver comunidade é preciso que existam crenças e aspirações comuns, sendo imperativo comunicá-las.

Uma vez estabelecido o significado de comunicação em seu nexo com a vida social, Dewey (1959a, p. 10) esclarece o sentido da palavra educação: "educação consiste primariamente na transmissão por meio da comunicação". Faz-se, assim, um raciocínio que se apresenta na forma de um silogismo: se a socialização se faz pela comunicação, e se a educação se faz pela comunicação, então socializar é educar. Tal raciocínio busca mostrar a relevância da educação como processo que transforma os indivíduos em seres sociais, pois educar é o meio pelo qual se transmitem valores e conhecimentos, se difunde a experiência socialmente acumulada e se torna os indivíduos membros da comunidade. Trata-se de um recurso argumentativo que tem a nítida intenção de mobilizar para uma determinada ação, a ação de educar, com o intuito de garantir a existência da sociedade como tal. Esse argumento, que também pode ser expresso em forma silogística, é: se a socialização é decisiva para a existência da sociedade, e se educar realiza a socialização, conclui-se que é preciso educar, ou seja, educar é uma prática que merece atenção especial.

\section{A comunicação em ambiente escolar}

No pensamento deweyano, educar e comunicar são termos que se enlaçam freqüentemente, de tal modo que a elucidação de um conduz à explicitação de outro. Comunicar (e, portanto, educar) envolve sempre dois pólos, segundo Dewey: de um lado, há alguém já socializado, que detém os saberes e padrões socialmente aceitáveis e quer torná-los comuns; de outro, há um ser não plenamente socializado, que ainda não conhece os parâmetros da comunidade na qual está destinado a viver e que precisa conhecê-los. Esse processo, em que alguém comunica e alguém recebe conteúdos comunicados, difere de um para outro momento histórico, assumindo características peculiares de acordo com o tipo de sociedade em que se efetiva.

Em Democracia e Educação, Dewey explica que tal processo se dá desde os povos primitivos, mas a sua ocorrência em sociedades de estrutura simples transcorre na da convivência espontânea de adultos e crianças. Em sociedades complexas, isso não basta para que a experiência seja socializada, fazendo-se necessário formalizar os procedimentos educacionais, o que eleva o processo de comunicação a patamares de inigualável relevância para a solidez do grupo social. Diante da grande quantidade e da extensa variedade de valores e conhecimentos que caracterizam a civilização contemporânea, não se pode confundir educação informal com educação escolar.

Daí decorrem os atributos que distinguem o conteúdo da comunicação em ambiente escolar, na visão deweyana. Não é qualquer experiência que interessa transmitir pela educação formal, mas apenas aquelas de interesse direto da comunidade, que têm serventia para a sobrevivência da sociedade como tal. Assim, a educação deve cumprir dois objetivos estreitamente vinculados: conservar e transformar; reter das gerações passadas o que há de melhor e, ao mesmo tempo, superar modos ultrapassados de ver o mundo; adequar o novo ao

\footnotetext{
No presente trabalho, foram mantidos todos os grifos dos trechos transcritos.

2 Será mencionado o texto original dessa obra quando a versão brasileira não soar suficientemente precisa para expressar as idéias do autor.
} 
velho e, ato contínuo, ajudar os educandos a transgredirem padrões já estabelecidos. É assim porque a sociedade necessita permanecer articulada em torno de certos princípios e crenças, mas precisa também ser renovada para dar conta dos desafios por ela mesma criados. Caso um ou outro desses requisitos não seja cumprido, o agrupamento social aproxima-se do caos, quer pela imobilidade, quer pela fragmentação de suas instituições.

Conclui-se, então, que educar é comunicar, é transmitir padrões partilhados pela comunidade, como sempre tem sido desde tempos remotos; mais do que isso, porém, nas sociedades marcadas por avançado aparato científico, tecnológico, artístico e jurídico, a educação não pode ser reduzida a processos de comunicação informal, o que resultaria na valorização de reações espontâneas, hábitos conservadores e saberes provenientes do senso-comum, já em posse dos educandos. Educação escolar, então, é ofício a ser praticado por profissionais sintonizados com as necessidades de conservação e de superação da sociedade. Por fim, a educação não pode transmitir apenas conteúdos necessários ao aqui e agora, sendo fundamental manter abertos os canais da imaginação e da ousadia, com vista ao futuro.

\section{Escola, cultura e ciência}

O tema da transmissão de conteúdos por intermédio da escola conduz a uma reflexão sobre a escola contemporânea e seus condicionantes culturais, bem como à participação da ciência na educação. Em Philosophy of Education (Dewey, 1958, p. 149) lê-se que "A comunicação é o traço que definitivamente distingue o homem de outras criaturas; é a condição sem a qual a cultura não existe". A situação educacional existente, porém, é claramente cindida por dois modelos concorrentes de escola, o "liberal" ou "literário" e o "vocacional" ou "técnico", cada qual servindo à transmissão exclusiva de determinados aspectos da cultura. $^{3}$ Esse quadro leva à indagação quanto ao tipo de cultura que se quer transmitir por intermédio das escolas.

Dewey (1958, p. 29) considera que a proposta de extinguir a educação "técnica" em benefício do modelo "literário" carrega traços de medievalismo. Levá-la a cabo seria retornar a uma era em que as tradições culturais dependiam da interpretação, adaptação e organização de documentos escritos, bem como de sua transmissão por meio de rígidos padrões lingüísticos. Em face da desagregação do mundo europeu naquele momento histórico, fazia sentido manter a hegemonia das letras como recurso de comunicação, uma vez que os clérigos eram, de fato, os únicos detentores de ferramentas lingüísticas e autoridade moral capaz de preservar os bens culturais e transmiti-los pela educação.

Ao pleitearem o fim da educação "técnica" no momento atual da civilização, certos pensadores nada mais fazem do que acirrar o dualismo entre os dois modelos educacionais, os quais, isolados um do outro, são incapazes de formar o homem para a vida contemporânea. Por isso, em Democracia e Educação, Dewey (1959a, p. 149) considera necessário romper a dualidade do sistema de ensino e implantar a escola única para todos, com o intuito de unir, na mesma pessoa, "o homem 'prático' e o homem de teoria e cultura", o que só se viabiliza pela difusão da cultura científica nos diversos níveis da escolaridade.

Para Dewey (1959a, p. 149), a dicotomia entre a inteligência degradada "daqueles que fabricam e produzem" e a inteligência superior dos "que se emanciparam da disciplina do trabalho" persistirá "enquanto a sociedade for organizada com fundamento na divisão em classes trabalhadoras e classes não trabalhadoras". Mesmo assim, é preciso romper a dicotomia liberal-vocacional e promover o ensino pela ciência, para educandos de todas as classes sociais, indistintamente. Para os operários, em especial, trata-se de fomentar a superação do ensino que forma os alunos como "apêndices da indústria e do comércio" (Dewey, 1959a, p. 348) e leva à perpetuação da ordem industrial capitalista, impedindo que a educação contribua para transformá-la. ${ }^{4}$

\section{Ciência com o temperamento científico}

A visão deweyana que sugere educar por meio da ciência pode ser compreendida mediante a distinção entre "temperamento científico" e "técnica científica", expressões de Bertrand Russel que Dewey (1958, 
p. 172) adota em Philosophy of Education para discutir o livro Religion and Science, de autoria do pensador britânico. O primeiro conceito refere-se ao procedimento de assumir as conclusões científicas como provisórias, como hipóteses que podem ser refutadas mediante novas investigações, nunca como verdades eternas e imutáveis. O conhecimento assim produzido torna-se instrumental, isto é, relevante para produzir mais conhecimento e não para desvendar a essência eterna das coisas. ${ }^{5}$

É a isso que Dewey se refere quando pensa em educar - ou comunicar conhecimentos - pelo uso da ciência: uma educação que, em consonância com o genuíno espírito científico, transmita a noção de que verdades são convenções e não desígnios da natureza humana ou de Deus. Verdades científicas são úteis, uma vez que podem ser questionadas pela comunidade científica, dando margem, assim, a novas investigações, pois, afinal, ciência é apenas "algo que um grupo de pessoas, chamadas cientistas, faz", afirma o autor (1958, p. 173). ${ }^{6}$

Aplicando o mesmo princípio às verdades e às comunidades em geral, tem-se uma regra moral para a vida em sociedade - o princípio democrático. A educação assume o papel de instrumento para a construção de uma sociedade mais perfeita no futuro, compondo, assim, o principal elemento da "utopia democrática" de John Dewey, a qual propõe constante mobilização para alcançar um mundo melhor. ${ }^{7}$

O segundo conceito, "técnica científica", diz respeito aos métodos científicos de manipulação da natureza, geradores de tecnologias aplicáveis à vida do homem comum. A aplicação técnica da ciência prescinde das qualidades do "temperamento científico" e é, por excelência, avessa a admitir as limitações inerentes ao genuíno espírito investigativo. Ocorre que o prestígio da ciência advém de suas aplicações materiais, ficando o "temperamento científico" oculto da grande massa de usuários da tecnologia, pois a idéia de provisoriedade inerente à ciência não vem estampada na embalagem dos inventos produzidos para aplacar as nossas necessidades de proteção e conforto.

O problema está precisamente no fato de "a grande massa de pessoas tomar contato com a 'ciência' apenas em suas aplicações", afirma Dewey (1958, p. 162), pois isto produz efeitos devastadores na vida das pessoas, em especial no escopo de sua compreensão do mundo. Em vez de alargar os horizontes mentais do ser humano, a tecnologia acaba por obscurecer o processo pelo qual os seus próprios engenhos são fabricados. Por isso, ao contrário de acusar a ciência e o modelo de ensino que a veicula como promotores do esvaziamento da espiritualidade humana, Dewey prefere defender a inserção de mais ciência nas escolas. Não a "técnica científica", mas o "temperamento científico".

\section{O método de comunicar}

Diante dessas proposições, pode-se indagar sobre a melhor maneira de efetivar a educação: como educar, como comunicar, como transmitir conhecimentos e valores socialmente necessários, de tal modo que estes não permaneçam ossificados e possam viabilizar formas alternativas de convivência? Em Democracia e Educação, Dewey (1959a, p. 207) considera fundamental que o conhecimento seja ensinado sempre em estreita conexão com a experiência do educando. "Nada se objeta - diz o autor - a que as informações sejam expressas com palavras; a comunicação opera-se necessariamente por meio de palavras". Mas se o conteúdo comunicado não estiver "incorporado à experiência existente de quem aprende", a comunicação "converte-se em simples palavras, isto é, em puros estímulos sensoriais, desprovidos de significação".

Quando a experiência comunicada provoca tão-somente "reações maquinais", expressões da fala ou da escrita que só reproduzem os conteúdos veiculados, o ensino presta-se apenas à conservação, sendo inútil à superação do mundo existente. As informações transmitidas ao educando só adquirem sentido quando concatenadas para solucionar um problema, quando eficazes para livrar o estudante de uma situação problemática que ele já tenta desvendar por meios próprios. ${ }^{8}$ O conteúdo da comunicação só é significativo quando tem a potencialidade de instigar o aluno a utilizar os conhecimentos recebidos como alimento para uma situação problemática atual, servindo para o enfrentamento de ocorrências futuras.

É nesse contexto discursivo que se entende a conhecida expressão deweyana que contrapõe o lógico ao psicológico. Quando

\footnotetext{
Russel, citado por Dewey, diz: "Knowledge ceases to be a mental mirror of the universe and becomes a practical tool in the manipulation of matter".

6 Na análise das idéias deGonseth, Bachelard e outros, muito semelhantes às concepções aqui apresentadas, Perelman (1999, cap.X) as caracteriza como um novo racionalismo, uma"filosofia regressiva" baseada em uma nova visão de ciência.

7 Sobre esta noção, ver Cunha (2001b).

8 Sobre a relação entre saberes cotidianos e não-cotidianos na proposta pedagógica de Dewey, ver Cunha (2001a).
} 
9 Segundo Warde (1997, p. 294), a principal crítica de Dewey a Herbart não incide em sua "pedagogia mas na psicologia que informava", a qual "não teria levado em conta 'as funções ativas e especiais' que, presentes nos seres vivos, redirecionam recombinam as relações deste ser com o seu ambiente".

${ }^{10}$ Os termos A e B constituem o foro, elementos conhecidos que servem para explicitar C e D, integrantes do tema cujos valores se deseja estabelecer. Tratase de uma analogia quando foro e tema pertencem a áreas diferentes (Perelman; OlbrechtsTyteca, 2002, p. 424-425), como é o caso aqui: o primeiro não pertence ao domínio das atividades humanas, e o segundo, sim.

${ }^{11}$ No original, "human relationships"(Dewey, 1997, p. 5) relationships"(Dewey, 1997,p.5).
${ }^{12}$ No original, "Consensus demands communication" (Dewey, 1997, p. 5).

${ }^{13}$ Metáfora é "uma analogia condensada, resultante dafusão deum elemento doforo com um elemento do tema" (Perelman; Olbrechts-Tyteca, 2002, p. 453). comunicamos algo que temos sob nosso domínio, tendemos a fazê-lo de acordo com a ordem lógica consubstanciada na forma final do conteúdo comunicado, a forma supostamente definitiva do objeto em causa. É o que ocorre quando nos dedicamos a ensinar conhecimentos científicos, como ilustra Dewey (1959a, p. 241): "Ciência subentende um esforço inteligente e perseverante para rever as convicções correntes a fim de excluir delas o que é errôneo, aumentar-lhes a exatidão, e, acima de tudo, dar-lhes tal forma, que se tornem o mais manifestas possível as mútuas dependências dos vários fatos". Assim, "Lógica e pedagogicamente a ciência é a perfeição do conhecimento, é sua última fase".

E é precisamente o formato dessa comunicação que se torna obstáculo para o aprendiz, pois "a formulação da matéria é feita para promover o conhecimento como um fim em si mesmo", deixando "ocultas suas conexões com a matéria da vida quotidiana". O estudante acaba por aprender um conjunto de "símbolos sem a chave de sua significação", um "lastro técnico de conhecimentos informativos" que não lhe permite perceber neles "os objetos e atos que lhe são familiares; amiúde adquire simplesmente um vocabulário especial", completa Dewey (1959a, p. 242).

Abdicar do método lógico significa tomar como ponto de partida a experiência atual do estudante, requisito indispensável para levá-lo à compreensão daquela "perfeição do conhecimento", o objeto tal qual formalizado pela ciência em determinado momento histórico. A diferença entre a proposta deweyana e os sistemas pedagógicos tradicionais não está naquilo que se quer ensinar, mas no método de comunicar tais conteúdos, pois, para Dewey, é necessário abandonar o ensino por meio de fórmulas e leis, efetuado mediante o emprego da linguagem dos cientistas, substituindo-o pelo método da experiência com as coisas que são familiares aos estudantes, acessíveis ao seu campo cognitivo atual. ${ }^{9}$

\section{A metáfora máquina}

Essa proposta de método de ensino vincula-se estreitamente a uma certa concepção de sociedade, a qual Dewey explicita por intermédio da rejeição de uma metáfora construída com base na seguinte analogia: as partes de uma máquina (A) estão para a máquina (B) assim como as relações humanas (C) estão para a sociedade (D). ${ }^{10}$ Dewey (1959a, p. 5) afirma que a existência de um grupo social não se dá pelo simples fato de haver indivíduos vivendo em proximidade material ou trabalhando para um mesmo fim, como as partes de uma máquina, que "funcionam em conjunto para a obtenção de um resultado comum, mas não formam por isso uma comunidade". As partes da máquina só formariam uma sociedade se pudessem conhecer o fim comum que as une, o que lhes permitiria regular suas atividades específicas para a obtenção dessa meta.

Nos grupos humanos dá-se o mesmo. "Grande número de relações ${ }^{11}$ em todos os grupos sociais ainda se encontram no plano das peças das máquinas"; indivíduos "utilizam-se uns dos outros para obter resultados desejados, sem atender às disposições emocionais e intelectuais e ao consentimento daqueles de quem se servem". São relações em que prevalece "a superioridade física, ou de posição, habilidade, aptidão técnica e o domínio mecânico ou financeiro da aparelhagem ou dos instrumentos de trabalho". Para que as partes da máquina - analogamente, as relações humanas - constituíssem uma comunidade de fato, precisaria haver comunicação, troca de informações entre todos os envolvidos no processo, sobre os propósitos de cada um. Ou seja, precisaria haver comunicação para que se formassem consensos, pois consenso demanda comunicação. ${ }^{12}$

A metáfora pela qual Dewey caracteriza a sociedade contemporânea, ou pelo menos boa parte dos grupos sociais existentes, é formada pelos termos B e D da analogia: a metáfora sociedade-máquina, tipificada por relações humanas que se assemelham a partes de uma máquina. ${ }^{13}$ A rejeição dessa metáfora, por sua vez, possibilita compreender a concepção de sociedade aceita pelo autor: para que a humanidade saia do plano das máquinas e desenvolva a comunicação verdadeira, é imprescindível que "pais e filhos, professores e alunos, patrões e empregados, governantes e governados" formem um verdadeiro grupo social, que tenha objetivos verdadeiramente comuns e, mais do que isso, que comunique entre si tais objetivos para elaborar consensos.

Dados os vínculos entre educação e socialização, pode-se dizer que Dewey, ao 
recusar a metáfora social sociedade-máquina, recusa também uma metáfora escolar, a qual, por semelhança com a primeira, pode ser enunciada como escola-máquina, em que as relações estabelecidas no espaço escolar não contribuem para instituir propriamente uma escola, ou seja, um ambiente verdadeiramente educativo. Ambas as metáforas são rejeitadas por não contemplarem o modo específico de comunicação que consiste na transmissão de conhecimentos e valores calcados na transação entre os propósitos de cada um dos agentes envolvidos, um processo que prescinde da coerção, que respeita os componentes emocionais e intelectuais dos educandos e permite elaborar consensos, única maneira de realizar a verdadeira socialização. ${ }^{14}$ Vem daí a relevância do método de educar proposto por Dewey.

\section{Comunicação, educação e arte}

Em Democracia e Educação, Dewey acrescenta ainda outros atributos à comunicação e, conseqüentemente, ao método de educar. Para ser inteligentemente comunicada, a experiência deve ser submetida a um planejamento prévio, um processo pensado, intelectualmente elaborado, refletido, o que exige o exercício de conhecer, de modo imaginativo, a experiência dos receptores da mensagem veiculada. Assim, a educação, que se faz pela comunicação, envolve não só os conteúdos e valores a serem transmitidos, como também o método de transmissão - certamente o método psicológico, que leva em conta as peculiaridades dos educandos.

O trecho em que estas idéias aparecem deve ser transcrito:

É mister, com efeito, que se formule a experiência para ser comunicada. Esta formulação requer colocarmo-nos fora da mesma, vê-la como outra pessoa a veria, observarem-se os pontos de contato que ela tenha com a experiência pessoal da pessoa a quem vai ser comunicada, a fim de ser apresentada em tal forma que a dita pessoa lhe apreenda a significação. A não ser que se trate de lugares-comuns, precisamos conhecer, imaginando-a, a experiência de outras pessoas, para compreensivelmente lhe falarmos sobre nossa própria experiência. ${ }^{15}$ Toda comunicação é semelhante à arte. (Dewey, 1959a, p. 6)
Em seguida, Dewey apresenta uma conclusão: dessa forma, diz ele, pode-se afirmar que toda "prática social que seja vitalmente social ou vitalmente compartilhada" é educativa "para aqueles que dela participam". ${ }^{16} \mathrm{O}$ intuito do autor é perfeitamente claro, indicando que a comunicação, para assumir um caráter social e socializador, envolvendo os dois pólos dela participantes, deve ser adequadamente planejada.

A frase "Toda comunicação é semelhante à arte", porém, oferece certa dificuldade, se vista como recurso argumentativo destinado a elucidar o trecho que a precede; não se trata de uma analogia, não é um exemplo e nem mesmo uma ilustração, resumindose, portanto, ao estabelecimento de uma simples relação de semelhança. ${ }^{17}$ Ademais, seu fraco poder de argumento, no contexto em que está localizada, decorre de o significado da palavra arte não estar ainda elucidado, nesse ponto de Democracia e Educação. Assim, a frase em nada contribui para esclarecer, o que seria desejável, a comunicação e, por conseqüência, a educação.

Além disso, a expressão pode dar margem a inúmeras interpretações, o que não aconteceria se o conceito fosse de domínio comum, o que não é, ficando-se na dependência daquilo que o leitor entenda por arte. Se esse entendimento for calcado na idéia usual de que o vocábulo designa atividades baseadas na expressão momentânea de atributos individuais, sem qualquer planejamento de meios e fins, chega-se a uma conclusão que emerge em ambigüidade o posicionamento educacional deweyano. ${ }^{18}$ Cabe esclarecer, portanto, o sentido da palavra arte em Dewey.

\section{Os atributos da arte}

Encontra-se novamente o vocábulo arte nos capítulos 10 e 15 de Democracia e Educação, sendo que no primeiro deles assume uma feição nitidamente social e socializadora. Ao explicar a noção de interesse, componente fundamental de sua proposta pedagógica, ${ }^{19}$ Dewey (1959a, p. 148) considera que "as atitudes fundamentais dos homens perante o mundo são fixadas pelo alcance e qualidades das atividades de que participam", e apresenta a "atitude artística" como exemplo desse princípio, dizendo: "A arte não é puramente interior, nem puramente exterior; nem meramente mental, nem

\footnotetext{
${ }^{14}$ Ao caracterizar a"pedagogia moderna" no Brasil do início do século passado pela "metáfora dos ritmos impostos aos corpos e às mentes pela vida moderna, império da indústria e da técnica", Carvalho (1997, p. 280) utiliza o mesmo foro da metáfora rejeitada por Dewey. Isto significa que a autora descreve uma pedagogia diferente da deweyana (Cunha, 1999). No original, "one has to assimilate, imaginatively, something of another's experience in order to tell him intelligently of one's own experience" (Dewey, 1997,

p. 6).
No original, "It may fairly be said, therefore, that any social arrangement that remains vitally social, or vitally shared, is educative to those who participate in it" (Dewey, 1997,

p. 6).

${ }^{6}$ No original, "It may fairly be said, therefore, that any social arrangement that remains vitally social, or vitally shared, is educative to those who is educative to those who
participate in it" (Dewey, 1997, p. 6).

${ }^{17}$ Não é uma analogia porque ambos os termos pertencem ao mesmo domínio, são atividades humanas. O exemplo consiste na apresentação de um caso particular para fundamentar a regra que se deseja estabelecer, ao passo que a ilustração faz o mesmo com o intuito de reforçar a adesão a uma tese já aceita (Perelman, OlbrechtsTyteca, 2002, p. 407 e 424).

${ }^{18}$ No Brasil, essa interpretação de educação como arte foi muito bem apresentada e criticada por Jayme Abreu (1958), segundo referenciais deweyanos - ver Cunha (2001c).

${ }^{19}$ Ver Interest and Effort in Education, publicado no Brasil em Vida e Educação (Dewey, 1971).
} 
${ }^{20}$ Na versão brasileira, "enriquecimento sentimental ou intelectual". No original, "enrichment of emotion and intellect" (Dewey, 1997, p. 135).

${ }^{21}$ No original, "Work which remains permeated with the play attitude is art - in quality if not in conventional designation (Dewey, 1997, p. 206). A palavra play pode significar "brinquedo ou jogo", como na versão brasileira, conotando ludicidade.

${ }^{22}$ No original, "all of which had to be known in order that there be intelligent skill or art" (Dewey, 1997, p. 195)

${ }^{23}$ No original, "deliberate technical study"(Dewey, 1997, p. 185)

${ }^{24}$ No original, "three fairly typica stages in the growth of subject matter in the experience of the learner" (Dewey, 1997, p. 184)

${ }^{25}$ Em português, "pelo manuseio e familiaridade da criança com as coisas". No original, "in familiarity or acquaintance with things" (Dewey, 1997, p. 194), não consta a palavra "criança" ou qualquer menção a faixas etárias, pois o autor descreve um processo cognitivo que independe da idade. simplesmente material. Como qualquer outra espécie de atividade, a arte produz mudanças no mundo", mas difere das atividades que podem ser chamadas mecânicas, em que as mudanças produzidas não são acompanhadas de enriquecimento da emoção e do intelecto de seus praticantes; $;^{20}$ difere também de práticas que visam apenas "o ornamento exterior, a ostentação".

Vê-se que Dewey confere à arte um caráter que transcende o plano estritamente individual, âmbito em que a vida mental se identifica com a mera "contemplação de uma paisagem interior". Trata-se verdadeiramente de arte quando o executante tem sua inteligência e seus objetivos próprios envolvidos na ação que desempenha, razão pela qual os seus sentimentos e idéias tornam-se meios para transformar as condições existentes. Para Dewey, a atitude artística é incompatível com a inclinação para refugiar-se em uma "representação interior de sentimentos e de fantasias" que nada mais faz do que levar as pessoas a se voltarem para si mesmas.

No capítulo 15 do mesmo livro, Dewey (1959a, p. 223 e 226-227) atribui à arte um caráter de atividade que se desenvolve mediante planejamento. Para advogar o uso da arte na educação, o autor afirma que arte - em essência, se não pela designação convencional - é trabalho permeado pela atitude de jogo ou brinquedo. ${ }^{21}$ Ao contrário do que usualmente se pensa, jogar e trabalhar não são ações inconciliáveis, só assumindo posições conflitantes em determinadas condições sociais, particularmente quando se coloca a obrigação de "executar tarefas por imposição externa". Trabalho e brinquedo são, então, definidos por Dewey como "ocupações ativas" que não se opõem uma à outra, porque ambas "subentendem fins conscientemente demandados, e seleção e adaptação de materiais e processos destinados a conseguir os desejados fins".

Desfaz-se, assim, qualquer sombra de ambigüidade porventura presente na frase "Toda comunicação é semelhante à arte". Toda comunicação é semelhante à arte porque os dois vocábulos possuem os mesmos atributos: designam atividades socializadoras que envolvem a totalidade emocional e intelectual de seus participantes, ultrapassando o âmbito meramente individual; comunicação e arte são práticas que buscam alterar o estado atual das coisas, e atingem seus objetivos quando pautadas em ações racionalmente planejadas, mediante perfeito domínio de meios e fins.

\section{Os três estágios do conhecimento}

Tanto a palavra arte, em português, quanto art, do idioma inglês, vêm do latim ars, que é a versão do grego techné. Em Democracia e Educação há poucos indícios da etimologia do vocábulo tal qual o autor o emprega, mas no capítulo 15 o termo arte é associado a techné. Ao usar a palavra, grafada em grego no original, Dewey lembra que Platão via as atividades dos "sapateiros, carpinteiros, músicos, etc.", como possuindo tudo o que tinha que ser sabido para haver habilidade inteligente ou arte. ${ }^{22}$ A referência é feita para explicar que trabalho e jogo "correspondem, ponto por ponto, aos característicos da fase inicial do ato de aprender", a qual é caracterizada como a que "consiste em aprender como fazer as coisas e no familiarizar-se com as coisas e processos aprendidos ao fazê-las" (Dewey, 1959a, p. 215).

No capítulo anterior do mesmo livro, essa mesma fase é definida como a que se dá em situações descritas como "aprender fazendo" (Dewey, 1959a, p. 204). Essa expressão, learning by doing no original em inglês (Dewey, 1997, p. 184), costuma ser empregada para caracterizar toda a proposta educacional deweyana, com evidentes implicações epistemológicas. Na verdade, como se vê, o "aprender fazendo" designa apenas um dos estágios do processo de aprendizagem, precisamente aquele que origina "todos os nossos conhecimentos que não resultam de deliberado estudo especial", ${ }^{23}$ como afirma Dewey (1959a, p. 205). O conhecimento contido na arte, ou techné, como o autor a qualifica, não traduz o ápice da possibilidade de conhecer, pois na experiência do aprendiz há "três estágios perfeitamente típicos" quanto ao "desenvolvimento da matéria a aprender". ${ }^{24}$

No primeiro estágio do learning by doing, o conhecimento "é uma habilidade inteligente" que se expressa por meio da familiaridade com as coisas. ${ }^{25} \mathrm{O}$ segundo se dá gradualmente, à medida que o conhecimento assim adquirido "se avoluma e aprofunda por meio dos conhecimentos ou informações comunicados". O terceiro estágio, por fim, advém das conexões que se 
fazem de maneira "lógica ou racionalmente", constituindo o tipo de conhecimento que é de domínio dos experts na matéria (Dewey, 1959a, p. 203).

$\mathrm{O}$ que faz com que o conhecimento obtido no "aprender fazendo" seja elevado à posição superior é a associação do indivíduo a empreendimentos comuns; é o contato com "as coisas que os outros nos comunicam", as quais se fundem à experiência particular (Dewey, 1959a, p. 205). É justamente nesse ponto que se apresenta o papel decisivo da comunicação, que deve ser adequadamente planejada para que os conteúdos comunicados não se convertam "em puros estímulos sensoriais, desprovidos de significação", o que levaria o destinatário da informação a meras reações mecânicas (Dewey, 1959a, p. 207). ${ }^{26}$

Quando o saber adquirido por meio da efetiva comunicação com os outros é elevado a um patamar ainda superior, assume o caráter de conhecimento científico, uma vez que a ciência é o "saber em sua mais característica forma". O que se conhece, nesse plano, "é certo, seguro, assente"; é "antes aquilo com que pensamos, do que aquilo sobre que pensamos". Não se trata de tomar o conhecimento científico como sinônimo de verdade eterna e imutável, pois a ciência, para Dewey, está sempre atada ao temperamento científico, conforme já foi mencionado.

Para chegar a esse terceiro estágio, fazse mais uma vez imprescindível a comunicação, pois a ciência, como Dewey (1959a, p. 209) a qualifica, é "artificial (é uma arte criada $)^{27}$ e não espontânea; aprendida, e não inata". Sendo assim, os aprendizes não chegam espontaneamente ao conhecimento científico, seja pelo "aprender fazendo", seja pelo simples contato com experiências alheias. Exige-se, então, um tipo especial de comunicação que viabilize "a iniciação no espírito científico", que dê aos educandos a posse "dos melhores instrumentos que a humanidade inventou para orientar eficazmente o raciocínio".

\section{A distância dos gregos}

Dewey menciona a filosofia grega em muitas de suas obras, com intuitos e em contextos muito diversificados, com diferentes graus de profundidade e clareza, o que torna impossível discorrer mais amplamente sobre o assunto neste trabalho. O que se pode dizer é que Dewey (1959a, p. 278) é enfático em apontar as profundas dicotomias geradas pela divisão social vigente na Grécia Clássica, onde as atividades produtivas eram desenvolvidas por uma classe servil, deixando outra classe livre para ocupar-se com os assuntos do intelecto e da política e para usufruir o tempo livre na forma de lazeres. Por isso, Dewey procura distanciar-se das concepções gregas, em especial quanto à educação e à ciência, conforme ele as entende.

Em Democracia e Educação (Dewey, 1959a, p. 278), lê-se que Aristóteles distinguia com exatidão "dois tipos de educação: a baixa ou mecânica e a liberal ou intelectual", pois havia, de fato, dois tipos de atividades ou "artes", ${ }^{28}$ as servis e as livres, a que correspondiam a experiência e a razão, respectivamente. Dewey (1959a, p. 288) considera que Platão e Aristóteles "concordavam em identificar a experiência com os interesses puramente práticos" apartados do conhecimento existente por si mesmo, o conhecimento que se faz "livre de associações com a prática"; a experiência, para os gregos, "sempre subentendia falta, necessidade, desejo", ao passo que o conhecimento racional era visto como "completo e compreensivo, em si mesmo".

Em Philosophy of Education, Dewey (1958, p. 286) enfoca o mesmo assunto, enfatizando que o sistema filosófico clássico, oriundo de Aristóteles e firmado na era medieval, postula a existência de um grau superior de conhecimento relacionado com certas formas inerentes ou naturezas, as essências próprias do Ser, eternas, fixas, imutáveis e necessárias. Para Dewey, tal abordagem significa negar o alicerce dos três estágios do conhecimento, todo ele fundamentado na experiência, seja a do próprio aprendiz, no learning by doing, seja a que é comunicada por outrem, nos dois âmbitos subseqüentes da aprendizagem.

O cerne da crítica deweyana pode ser sumariado na concepção de mundo que atribui aos gregos. Ao refletir sobre a tradição do pensamento ocidental no livro Reconstrução em Filosofia, de 1920, Dewey (1959b, p. 82) afirma, generalizando, que "o mundo em que até os homens mais inteligentes dos tempos idos julgavam viver" era "um mundo fixo, um domínio onde qualquer mudança somente se processava dentro de limites imutáveis de inação e de

\footnotetext{
${ }^{26}$ Em Art as Experience, obra de 1934, Dewey (1980, p. 244) afirma que a arte atinge seus objetivos socializadores devido à comunicação, que é o processo de criar participação, tornar comum aquilo que antes era isolado e singular.

${ }^{27}$ No original, "an acquired art" (Dewey, 1997, p. 189)

${ }^{28}$ No original, "To these two modes of occupation, with their distinction of servile and free activities (or 'arts') correspond two types of education" (Dewey, 1997, p. 253). A versão brasileira suprimiu o trecho entre parênteses.
} 
permanência", formado por "reduzido número de classes, espécies, formas, distintas e separadas em qualidade ... e dispostas numa ordem graduada de superioridade e inferioridade".

Dewey, por sua vez, concebe o mundo em permanente mudança, idéia que os antigos não teriam apreendido. ${ }^{29}$ Só a era moderna permitiu à ciência ocupar-se do conhecimento relativo à mudança, implicando operações deliberadas em consonância com um projeto que coincide com uma hipótese ativa, continuamente testada no intuito de reformular o conhecimento estabelecido. Dewey (1958, p. 291) entende que a ciência dos modernos se distingue de outros modos de conhecimento porque as operações de busca (search) que constituem a arte ou destreza desenvolvem-se, nesse caso, como pesquisa (re-search), ou seja, como investigação destinada a desvendar a realidade do mundo em constante transformação, sem o apoio de instâncias metafísicas. Só então a ciência, "com respeito tanto ao método quanto às conclusões, é uma arte".

\section{A semelhança dos gregos}

Embora seja esse o posicionamento de Dewey ante os gregos, do que foi exposto no presente trabalho há alguns tópicos que chamam a atenção de maneira tão imediata que merecem ser tratados, ainda que de passagem, a título de indicação para futuros estudos.

\subsection{O conhecimento}

O primeiro tópico refere-se aos estágios do conhecimento, assunto que, associado aos significados de arte e ciência, guarda certa semelhança com as concepções de Aristóteles, em especial quanto à hierarquia dos vários modos de conhecer. Dewey não vincula suas idéias ao filósofo de Estagira, mas pode-se vê-las na tese aristoteleciana de que a experiência é a base do conhecimento inerente à arte (techné) e que a arte é superior à experiência, precisamente por referir-se à espécie e não ao indivíduo.

O célebre exemplo dado na Metafísica

${ }^{29}$ Para melhor elucidação dessa idéia e de suas repercussões no pensamento educacional brasileiro, ver Cunha (2001c). diversos indivíduos é próprio da experiência, mas ter a noção de que um certo remédio tem serventia para todos os indivíduos que apresentam os mesmos males é próprio da arte. Diferentemente da experiência, na arte faz-se "um nexo universal entre uma certa causa, por exemplo a característica de ser fleumático ou bilioso, e um certo efeito, por exemplo o fato de um certo remédio ser proveitoso" (Berti, 1998, p. 160).

O valor conferido por Dewey ao conhecimento associado à arte coincide com a noção de Aristóteles, segundo a qual a arte se faz acompanhar pelo "lógos verdadeiro" que permite o estabelecimento de vínculos não apenas entre casos individuais, mas destes com o universal (Berti, 1998, p. 160). Para o filósofo grego, uma atividade é nomeada arte quando imbuída de uma "representação mental, independentemente da matéria", o que modernamente se denomina "projeto" (Berti, 1998, p. 162), qualificativo que em Dewey é assumido pela idéia de planejamento, conforme já visto aqui.

A tese deweyana de que há um tipo de conhecimento, o conhecimento científico, ainda superior ao que é próprio da experiência e da arte assemelha-se à definição aristoteleciana de ciência (epistéme). Embora a arte possua uma racionalidade que a aproxima da ciência, pois o lógos que a caracteriza "é o conhecimento do porquê, ou seja, o conhecimento científico", Aristóteles afirma que a ciência está além disso, dado que se ocupa do conhecimento das causas e das realidades necessárias, desprendidas das realidades contingentes que dependem da ação humana (Berti, 1998, p. 162).

\subsection{A filosofia prática}

O segundo tópico que relaciona o pensamento de Dewey aos gregos diz respeito ao argumento que é empregado logo no início de Democracia e Educação para colocar em destaque a relevância do processo de educar, conforme já mencionado na primeira seção do presente estudo. Trata-se de um argumento que exibe os traços do que Aristóteles denomina silogismo prático ou silogismo falso, o qual expressa "uma forma de racionalidade" que é diferente da "racionalidade da ciência" (Berti, 1998, p. 152), cujo caráter é demonstrativo. No silogismo científico, as premissas maior e menor "são a causa necessária e ao mesmo 
tempo suficiente da conclusão, por isso a conclusão resulta necessariamente delas" (p. 5). O exemplo clássico é: "se todo homem é mortal, e se Sócrates é homem, então Sócrates é mortal".

As premissas do silogismo prático, por sua vez, exprimem, respectivamente, um fim a ser alcançado e um meio pelo qual se pode atingi-lo, sendo o seu resultado uma ação. É o que se pode ver no argumento deweyano em que a premissa maior é "a socialização é decisiva para a existência da sociedade" e a premissa menor é "educar realiza a socialização". As duas premissas não cumprem as várias exigências de um silogismo científico (Berti, 1998, p. 5-6), inclusive porque não constituem realidades evidentes, carecendo de demonstração para serem aceitas como tais. Identificamse, porém, com a definição de silogismo prático: a maior expressa um fim, que a socialização se efetive para que a sociedade exista, e a menor indica um meio, a educação como instrumento socializador. A conclusão, que não decorre necessariamente das premissas, incita a considerar a educação uma práxis relevante.

Para Aristóteles, ocupar-se com a ação é uma característica da filosofia prática, denominação que advém "do objeto desta ciência, constituído pelas coisas 'praticáveis', isto é, pelas ações, pela 'práxis', que têm princípio na escolha, na iniciativa do homem" (Berti, 1998, p. 117). Diferentemente da filosofia teorética, que busca apenas conhecer o porquê de as coisas estarem como estão, a filosofia prática tem compromisso com a instauração de "um novo estado de coisas", procurando "conhecer o porquê do seu modo de ser apenas para transformá-lo" (p. 116). A filosofia política, como também a chama Aristóteles, é prescritiva, pois pretende realizar o bem não só do indivíduo, mas "de toda a cidade (pólis)". Não parece ser outro o objetivo de Dewey, que, com seu silogismo falso, coloca a educação como prática que decide o destino da sociedade.

\subsection{A retórica}

O terceiro tópico deweyano que merece destaque é o da comunicação, igualmente analisado pelo filósofo estagirita, para quem o vocábulo arte também designa as "ciências poiéticas", a poética e a retórica, que não se dedicam às coisas, mas sim às palavras. A retórica, em particular, é a arte dos discursos, mais precisamente a arte de produzir discursos persuasivos, ou seja, argumentações (Berti, 1998, p. 164). Existe uma sensível diferença entre o discurso retórico e o discurso que emprega estritamente os recursos da lógica, sendo que o último ocupa-se de articular premissas para afirmar uma conclusão, atendo-se tão-somente ao aspecto formal das mesmas, visando excluir as ambigüidades presentes na língua natural (Perelman, 1999, p. 93).

É certo que se pode ensinar por intermédio desse recurso, a exemplo do que faz um cientista ao demonstrar o caráter necessário de certas conclusões diante de determinadas premissas. No entanto, tal discurso "é, na essência, um monólogo", uma vez que os ouvintes "não têm nada a dizer e devem somente aprender, isto é, ser ajudados a ver com clareza o que lhes é ainda obscuro" (Berti, 1998, p. 11). Quando se ensina dessa maneira, tem-se em vista um auditório universal, um público idealizado que não expressa particularidades sociais ou psicológicas, e que supostamente acata as premissas do orador (Perelman, 1999, p. 73).

O método preferido por Dewey, o chamado método psicológico, sugere que a educação considere um auditório particular, composto por estudantes, categoria de ouvintes que usualmente não partilha das premissas do orador, dado que suas experiências não emanam da ciência, mas do sensocomum, do reino da opinião. O discurso lógico, tão competente para demonstrar teoremas, não mobiliza as energias intelectuais e emocionais necessárias ao aprendizado, nesse caso. Para tornar a comunicação efetiva, então, faz-se necessária a arte de argumentar, que envolve o domínio de meios de persuasão dos interlocutores.

Quando o que se busca não é a elaboração de juízos puramente formais, os raciocínios da lógica formal não se aplicam; em tais circunstâncias, "a argumentação tem que ser retórica" (Perelman, 1999, p. 87). Por esta via de raciocínio, pode-se ousar atribuir um sentido à frase "Toda comunicação é semelhante à arte", a qual adquire forte poder argumentativo quando compreendida nesse prisma: toda comunicação é semelhante à arte da argumentação, pois a comunicação, para ser efetiva, deve inspirar-se na arte retórica. 


\section{Referências bibliográficas}

ABREU, Jaime. Filosofias da educação e pesquisa educacional. Educação e Ciências Sociais, Rio de Janeiro, v. 3, n. 7, p. 91-97, 1958.

BERTI, Enrico. As razões de Aristóteles. Trad. Dion Davi Macedo. São Paulo: Loyola, 1998.

CARVALHO, Marta M. C. Quando a história da educação é a história da disciplina e da higienização das pessoas. In: FREITAS, Marcos C. (Org.). História social da infância no Brasil. Cortez: São Paulo, 1997.

CUNHA, Marcus Vinícius. John Dewey, a outra face da Escola Nova no Brasil. In: GHIRALDELLI JÚNIOR, Paulo (Org.). O que é filosofia da educação? Rio de Janeiro: DP\&A, 1999.

. Dewey, Escola Nova e construtivismo: continuidade, descontinuidade e recontextualização. In: ALMEIDA, Jane S. (Org.). Estudos sobre a profissão docente. São Paulo: Cultura Acadêmica, 2001a.

. John Dewey: a utopia democrática. Rio de Janeiro: DP\&A, 2001b.

. John Dewey e o pensamento educacional brasileiro: a centralidade da noção de movimento. Revista Brasileira de Educação, Rio de Janeiro, n. 17, p. 86-99, maio/ago. 2001c.

. Ensino profissional: de Anísio Teixeira, o signatário incógnito do Manifesto de 1932, às concepções de John Dewey. In: VALE, José M. F. et al. (Org.). Escola pública e sociedade. São Paulo: Saraiva/Atual, 2002.

DEWEY, John. Art as experience. New York: Perigee Books, 1980.

. Democracia e educação: introdução à filosofia da educação. 3. ed. Trad. Godofredo

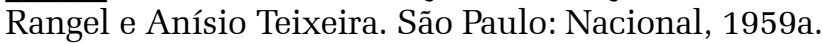

. Democracy and education: an introduction to the philosophy of education. New York: The Free Press, 1997. 1958.

. Philosophy of education: problems of men. Ames: Littlefield, Adams \& Co.,

Reconstrução em filosofia. 2. ed. Trad. António Pinto de Carvalho. São Paulo: Nacional, $1959 b$.

. Vida e educação. 7. ed. Trad. Anísio Teixeira. São Paulo: Melhoramentos, 1971.

PERELMAN, Chaïm. Retóricas. Trad. Maria Ermantina G. G. Pereira. São Paulo: Martins Fontes, 1999.

PERELMAN, Chaïm; OLBRECHTS-TYTECA, Lucie. Tratado da argumentação: a nova retórica. Trad. Maria Ermantina Galvão. São Paulo: Martins Fontes, 2002.

WARDE, Miriam. Para uma história disciplinar: psicologia, criança e pedagogia. In: FREITAS, Marcos C. (Org.). História social da infância no Brasil. São Paulo: Cortez/USF, 1997. 
Marcus Vinicius da Cunha, doutor em História e Filosofia da Educação pela Universidade de São Paulo, é professor associado do Departamento de Psicologia e Educação da Faculdade de Filosofia, Ciências e Letras de Ribeirão Preto (USP).

mvcunha@yahoo.com

\section{Abstract \\ Communication and art, or the art of communication on John Dewey}

The purpose of this paper is to elucidate the ideas of John Dewey expressed in the formulation that links education, communication and art. Moreover, as a methodological approach, it intends to show that every text must be analyzed in its discursive strategies, like a set arranged to assert some concepts. The starting point is the relevance of communication in the educational processes, attributed by Dewey in "Democracy and Education". The analysis of this and other books by the author allows to clear the concepts of science and art, as well as the method of teaching proposed by Dewey. The conclusion suggests that other investigations must study the Deweyan concepts in its possible links with Greek philosophy. rhetoric.

Keywords: communication and teaching; art and education; theories of knowledge;

Recebido em 16 de março de 2005.

Aprovado em 26 de agosto de 2005. 